\title{
Navigating Virtual Heritage Applications for Historic Cities in the Middle East
}

\author{
Mohamed Gamal Abdelmonem \\ School of Architecture, Design \& Built Environment \\ Nottingham Trent University \\ Nottingham, United Kingdom
}

\begin{abstract}
This paper discusses conceptual and practical framework for the development of virtual heritage platforms as a research, educational and engagement tool that brings historic spaces and buildings back to the recognition of the public eye of the ordinary user. It not only reproduces historical scenes through physical modelling of archaeological sites or data, but, more importantly, through serial narratives where life is explored and practiced in motion, and where cultural-feed brings meaning, experiences and understanding to the socio-cultural context. The paper first introduces a brief and summary database of case studies of examples of virtual heritage platforms and outputs that are suitable to different purposes and audiences. It, then, looks at the context and production of VH in Egypt, as an example of Middle Eastern cities with vast heritage sites and advanced technological provisions. It reports on the process and findings of an AHRC-funded project, Virtual Heritage Cairo, that aimed to investigate difficulties, technological and skill gaps amongst stakeholders and local start-ups that would otherwise enable VH in Egypt to become regional power.
\end{abstract}

Keywords-Virtual Heritage; Digital Visualisation; Cultural Heritage; Architectural History

\section{INTRODUCTION}

Iconic heritage is increasingly threatened by terror, climate change, rampant commercialisation, and overexploitation by tourism; and in some cases, by significant disinvestment. Lack of responsible planning, maintenance and preservation strategies have equally caused unmitigated dereliction and irreversible damage to many heritage sites and cultural traditions in the medieval Middle East. With the increasing rate of destruction of heritage sites, such as Palmyra in Syria, digital preservation of historic artefacts and cultural heritage has become an international priority. There are strategies, practices, skills and technologies that can protect, develop and sustain these places in other forms of reproduction such as digital modelling, immersive virtual and augmented reality, and cinematography and Audio-visual archives.

Virtual environments which encompass cultural heritage and are represented through digital media are often categorised as 'virtual heritage'. Modern media and technologies offer the possibility to experience virtually reconstructed historic sites as visitors, travelers, or even as a resident. Much of the effort in $\mathrm{VH}$ is directed towards accurate representation of historic objects and physical precision of ancient architecture styles but lacks the human part of city life, to which people can actually relate (Yang et al. 2006). Perfectly modelled virtual buildings and spaces only give a sense of precision, but only rituals, human attitude and cultural traditions enable them to engage with heritage visualisation (Mosaker 2001). Although virtual heritage possesses great potential to reconstruct our heritage and memory, critics often blame high cost, sophisticated hardware and software requirements, inaccessibility of technology and training, and high maintenance for preventing widespread dissemination and use of virtual heritage platforms. Virtual Heritage Environments (VHE) also lack 'thematic interactivity' due to the limited cultural content and engaging modules largely used in photorealistic video gaming systems.

For effective engagement with learning experiences and studies of ancient cultures or to grasp the implications of their evidence, it has become essential to introduce an interactive approach in 3D platforms. Cultural content of Virtual Heritage focuses on the potentials of reducing technical limitations and addition of sub-grid cultural terrains to attain a degree of 'reality' and photorealism of culture as a measure for virtual environments; leading towards the amorphous nature of history. As noted by Sanders (2008), "We understand that the past did not happen in $2 \mathrm{D}$ and that it cannot be effectively studied or taught as a series of disconnected static images". Due to advanced computer hardware and high-end graphics cards, trends in virtual reality applications are motivated towards the use of immersive technology for real-time interaction with high detail.

The first use of virtual heritage as a museum exhibit, and the derivation of the name 'virtual tour', was in 1994, as a museum visitor interpretation, providing a 'walk-through' of a 3D reconstruction of Dudley Castle in England as it was in 1550. This consisted of a computer controlled laserdisc-based system designed by British-based engineer Colin Johnson (Sanders 2008). It is a little-known fact that one of the first users of Virtual Heritage was Queen Elizabeth II, when she officially opened the visitor centre in June 1994. Because the Queen's officials had requested titles, descriptions and instructions of all activities, the system was named Virtual Tour, being a cross between virtual reality and Royal Tour (ibid).

Virtual, visual and digital display of lost heritage has inherent values in the education process for students in both pre-university as well as graduate education. For architecture and archaeological students, in particular, it virtually transfers 
them to another world and makes them feel as if they were walking at the site with its details in the past. For conservators, historians and archaeologists, it helps develop a rich library and digital archive of details, information and data necessary in restoring historical sites, as well as heritage preservation where the 3D virtual models contain accurate data and help for restoration. In this paper, I aim to uncover a conceptual framework for the development of virtual heritage platforms as a research, educational and engagement tool that brings historic spaces and buildings back to the recognition of the public eye of the ordinary user. It not only reproduces historical scenes through physical modelling of archaeological sites or data, but, more importantly, through serial narratives where life is explored and practiced in motion. The paper introduces an analytical approach to virtual heritage platforms including techniques, contexts, and outputs that are suitable to different purposes.

\section{The InTERface BetweEn ArChitectural, Cultural AND VIRTUAL HERITAGE}

The use of computer and digital applications for the preservation of heritage has as long history as computer science itself. Since the 1990s evolution of digital modelling, graphics, visualisation platforms and virtual environments have driven the development of new theoretical and empirical methods to approach the problems of archaeology and heritage preservations. Early methods of digital archaeology or archaeological computing were seen as methods for the elaboration of archaeological data using quantitative computing. Later versions contributed to the representation of archaeological data using cognitive procedures. Virtual Archaeology, in this context, has become a primary discipline in the analysis of the procedures of management, interpretation and representation of archaeological evidence using 3D computer graphic techniques. Its breakthrough in the digital reconstruction of historic events, lost structures or disappeared heritage enabled both theoretic and applied research to test different propositions, narratives and undertake forensic examination and analysis of archaeological remnants of the past.

However vastly developed over almost half a century, Virtual Archaeology (VA) remained a specialised platform for researchers and archaeologists for research-led activities. The public was not involved in its applications, and nor were its outputs intended for public consumption and use. More recently, the development of new communicative approaches to heritage, history and archaeological contents have progressed the use of interactive strategies that benefit broader groups of beneficiaries, stakeholders and public users. The proliferation of the use of 3D modelling techniques, nonintrusive imaging, geophysics and augmented reality cameras has offered a multiplicity of platforms to simply store, archive and communicate vast amounts of information on cultural heritage sites, traditions and contents. There was a simultaneous necessity to experience new sustainable ways to record, store, archive and analyse ever expansive records of datasets and to create the best medium to communicate digital systems of preservation.

Cultural institutions, on the other hand, are immersed in connecting with aspects of history and tradition. Their prime purpose is to bridge time, space and experience between the past and the contemporary audience and visitors. Technology offers new frontiers that help widen both platforms of engagement and number or type of regular audience. In a recent article in the Guardian newspaper, Mia Ridge and Danny Birchall (2015) suggested that while people may no longer be missing out on all that cultural heritage has to offer online because of their lack of internet access, there may be a new "digital divide" focused on social media platforms of display. Museums and exhibition managers are therefore contemplating whether the contemporary technology-hungry younger generation, or "digital natives", are receiving appropriate content.

Many digital projects have become an increasingly core element of museums' strategy as cultural institutions face up to the challenge of bridging the gap between their capacity with technology and their aspirations to enhance audience engagement with collections. (Ridge \& Birchall 2015). To achieve that, they very often make alliances with areas of digital expertise in the large and creative tech industry. There are several projects that explore culturally heritage sites and objects using digital means. For instance, museums are investigating the possibilities offered by $3 \mathrm{D}$ printers to examine their collections in a form where detail can be magnified and destruction is far less consequential. The Neues Museum in Berlin, for example, has collaborated with CultLab to scan and develop a virtual Model of the Nefertiti Bust to enable a larger group of audience to visualise the details of the masterpiece without exposing the invaluable artefact to damage.

Drones, 3D printing and augmented reality apps are just some of the tools being used to construct "virtual museum" experiences for real and digital visitors. Digital and virtual technologies open up new and exciting possibilities for exhibitors, archaeologists, architects and curators; they also provoke much debate in museums and user groups over real versus virtual users and the priority for investment. This instigates resistance around the issues of authenticity, ownership and value, among conventional and advocate archaeologists (Kidd, 2015.) There are currently a number of projects under way that explore how historically or culturally significant sites and objects can be presented using digital means. For instance, museums around the world are investigating the possibilities offered by $3 \mathrm{D}$ printers to extend and further examine their collections in a form where detail can be magnified and destruction is far less consequential.

Meanwhile, the EU's DigiArt project use drones and 3D Laser scanners, and $£ 60$ cameras to "capture" inaccessible cultural artefacts, before creating advanced 3D representations of them. DigiArt (2017) claims to provide innovative 3D capture systems, including aerial capture via drones, automatic 
registration and modelling techniques for post-capture processing, semantic image analysis and digital 3D representations via a "story telling engine". It uses augmented and virtual reality technologies for viewing, or interacting with the $3 \mathrm{D}$ models as a pathway to deeper understanding of artefacts. The $3 \mathrm{D}$ data captured by the scanners and drones, using techniques such as laser detection and ranging (LIDAR), are processed through robust features that cope with imperfect data. The major output of the project is a multifaceted system to be used by museums to create such a revolutionary way of viewing and experiencing artefacts.

The networks of virtual museums are expanding with environments where immersive $3 \mathrm{D}$ story worlds become a genuine possibility for historical encounters with heritage sites, either existent or disappeared. The Neues Museum, the Louvre, Victoria \& Albert all offer online Virtual Tours curated for public audiences and children (Kidd, 2015.) These applications for children are particularly important. Many cultural institutions, galleries and museums have developed augmented reality games that help children engage with historic sites or heritage stories through treasure hunts or collections of artefacts. It is not uncommon to find museums rendered in Minecraft, built by an invisible crowd of techsavvy fans, as in the British Museum's Museumcraft, or Tatecraft (ibid.). In this discourse, the rhetoric of authenticity has been debated and contested as opposed to originality. Authenticity has traditionally been key to the way museum experiences are packaged and displayed to the public users. But more recently, as History itself has become subjective, so have notions and concepts such as archaeology, originality and "authenticity", as they need an authority to justify the evidence behind its identification. The history and authenticity of an artefact is no longer absolute. Its meaning is relative to the audience as it was to its creator.

But these developments have been evolving over decades. People have been talking about virtual museums for many years as ways of allowing visitors access to sites and experiences that would never otherwise be accessible to them (Ibid.) What is remarkable is how far we have come to offer realistic interactivity with historic environments, and the way in which the boundaries between virtual and physical experiences have begun to blur. Being able to test new forms of reality that no longer exist raises intriguing aspects of rereading and reinterpreting history in the eyes of the audience, rather than the curator. Living the experience in the past venue is different from just watching still objects and images. Objects, images never exited out of context. For example, a Mummy never existed in daylight, nor the setting in which pharaonic artefacts were mostly discovered. Watching them in the tombs of Luxor or in Giza Pyramids has made them entirely more fearful than they are in the museums. Hence, virtual models of pharaonic tombs have been created to translate this experience to the virtual visitor in a way the normal museum could never offer.

\section{UNDERSTANDING VIRTUAL HERITAGE \& IMMERSIVE TECHNOLOGIES}

According to Erik Champion (2016), the application of virtual reality models and simulation technologies to historic and cultural heritage content is what we generally call virtual heritage, but it has so far eluded clear and useful definitions and it has been even more difficult to evaluate. Virtual heritage aims to recreate cultural heritage environments, as well as to people them and furnish them in a historically authentic way. It is designed to present historic information, context and practices as accurately, authentically and engagingly as possible. According to Addison (2000), virtual heritage is the fusion of virtual reality technology with cultural heritage content. Champion (2016), citing Stone and Ojika (2000, p73), defined virtual heritage as: "the Use of computerbased interactive technologies to record, preserve, or create artefacts, sites and factors of historic, artistic, religious, and cultural significance and to deliver the results openly to a global audience in such a way as to provide formative educational experiences through electronic manipulations of time and space." However, the idea of cultural content is rather limited and increasingly is under representative of several intangible aspects of cultural heritage; which were summarised by Champion (2013) \& Ch'ng (2013) as 'practices, representations, expressions, knowledge, skills - as the instruments, objects, artefacts and cultural spaces associated therewith - that communities, groups and in some cases, individuals recognize as part of their cultural heritage'

Whilst virtual heritage is used mainly as tools for teaching and learning about history in a visual manner, it has more recently been used to navigate, test and experiment different theories to validate historic and/or archaeological evidence. Aspects of authenticity, accuracy and realistic nature of the simulation, narratives and reproduction are intrinsic values that determine which version of history is at play. As history is increasingly contested due to different interpretations of evidence, being tangible or intangible, virtual heritage becomes accustomed to interpretation, contestation and analytical debate. Virtual heritage and cultural heritage, in such theoretical contexts, pose different and independent meanings; cultural heritage refers to sites, monuments, buildings and objects with historical, aesthetic, archaeological, scientific, ethnological or anthropological value, whereas virtual heritage refers to instances of these within a technological domain, usually involving computer visualisation of artefacts or Virtual Reality environments. Virtualisation is, however, much more complex and multilayered than visualisation that is to form a mental image of something incapable of being viewed or visible at a certain moment (Champion 2013). It involves the verification of not only the specific moment, site or context, but also narratives, practices and habits.

But Virtual heritage is becoming a leading sector in the diverse use of virtual reality systems and applications to engage communities, industries and technology developers with heritage. Thanks to the technological leap into a new 
generation of devices and supporting software, virtual heritage has become more inclusive than it was 20 years ago. While the 'London Charter' of 2009 defined computer-based visualisation as 'the process of representing information visually with the aid of computer technologies', scholars have demanded that this narrow definition is extended to include the non-visual aspects of visual experience, the haptic, auditory, olfactory and generally multi-sensory. According to Champion, it is not enough to reproduce a set of artefacts and archaeological objects as individual items separated from the story and context that give them meaningful representation.

In fact, Virtual Heritage Cairo argues that while visualisation of archaeological sites, objects and artefacts offers a detailed record of physical environments, those intangible aspects of heritage experience, namely, culturalfeed, would enable effective human interaction, understanding of the historic narratives in line with modelled objects. As we focus on cultural heritage, in contrast to archaeological preservation, we have to refer to the human sensory experience with history. Cultural geographers, in particular, tend to associate culture with what is not seen. According to Yi-Fu Tuan (1998), perceiving the intangible is at the foundation of all human culture. Then, as cultural heritage refers to historic periods and societies that no longer exist, we face the troubled task of how to virtualise aspects that are not visible, and whose evidence of existence is scattered items, objects, spaces and series of unconnected narratives.

Here Virtual Heritage emerges as a term that reflects the ambiguous and interpretative nature of its processes. It is 'an attempt to convey not just the appearance but also the meaning and significance of cultural artefacts and the associated social agency that designed and used them through the use of interactive and immersive digital media' (Champion, 2015, p95.). While we aim in this report to bring together a series of global examples and case studies database within the framework of innovative virtual heritage, it is important to offer critical insights into the context of this emerging field and market. This would debate arguments, potentials, difficulties and risks that virtual heritage promises as an innovative and emerging discipline, research field, creative industry, important sector and market.

\section{MODERN TECHNOLOGY AND CAPACITY TO RECONSTRUCT THE PAST}

It took quite a few decades for software engineering to develop software packages that effectively respond to the needs of archaeologists, architectural historians to provide platforms of engagement with historic environments. To see and walk through ancient places in ways that approximate the viewpoints of the original inhabitants is a perfect tool for teaching young students or to teaching ancient cultures and buildings in the digital age. To develop these environments modelling language had to be created and modelling techniques had to reach considerable maturity. This took a good 20 years of computer graphics and modelling language to catch up. Over the past decade, the applications and use of virtual heritage environments have expanded enormously.

Interactive $3 \mathrm{~d}$ virtual environments are usually coded using VRML (Virtual Reality Modelling Language) and experienced through multiple devices, whether specialist VR headsets, like Oculus Rift and HTC Vive which connect to computers, to smartphone-based adapted headsets using Web browser plugins (e.g., Cortona3d, FreeWRL), or built using game engines (e.g., Unity3d, Unreal) or specialty software (e.g., EonReality, Virtools) (Charara 2017). Once the headset and power source are secured, modelling and pre-rendered models are connected to the system. The synchronisation between the body and the model operates based on head tracking, controllers, hand tracking, voice, on-device buttons or trackpads. The development of these gadgets and devices is driven by the aspiration to perfection towards total immersion in the virtual world.

More advanced and professional platforms of display exist in specialist settings such as museums, university laboratories and Virtual Suites. CAVE, the Cave Automatic Virtual Environment, is a virtual reality display platform that consists of a cube-shaped dark VR room in which the walls, floor and ceiling are synchronised 3D aspheric projection screens (ibid). The user typically wears a VR headset or headup display (HUD) and interacts through input devices such as wands, joysticks or data gloves. Within such settings, "The worlds can be created, dynamically revised, visited, and populated in ways that offer near first-person simulations of the ancient world".

3-Point Cloud Laser Scanning, on the other hand, has introduced an innovative way to accurately record each detail and feature of the archaeological sites and buildings. The laser system characterises each point on the scanned object according to its colour and location in 3-dimensional space. It scans the surface of an object using one focused laser beam comprising three different wavelengths (red, green and blue), and records the reflected light using a "charge couple device" (CHIN 2009). Each point on the object is described by 6 numeric values; positional values $\mathrm{X}, \mathrm{Y}$, and $\mathrm{Z}$, and surface colour values $\mathrm{R}, \mathrm{G}$, and $\mathrm{B}$. Colour intensity and texture measurements of the surface are accurate, depending on the quality of the machine, being completely independent of ambient light. The most recent and advanced laser scanners provide a scanning resolution as fine as 100 microns, recording $3 \mathrm{D}$ shape and colour simultaneously with highresolution and perfect registration.

Technical applications of Virtual Heritage have expanded beyond the mere documentation and recording of individual objects. They are used in structural analysis, remote sensing, sensitive imaging and more broadly into regional conservation and planning strategies. The new and complex, yet highly accurate, LiDAR system has emerged as the leading technology in this field. LiDAR, an acronym for Light, Imaging, Detection And Ranging, is a development of the light and radar systems used for military applications. The 
principle behind LiDAR is simple; to shine a small light at a surface and measure the time it takes to return to its source. Light travels very fast - at about 300,000 kilometres per second, 186,000 miles per second or 0.3 metres per nanosecond, so turning a light on appears to be instantaneous.

The LiDAR instrument fires rapid pulses of laser light at a surface, some at up to 150,000 pulses per second. A sensor on the instrument measures the amount of time it takes for each pulse to bounce back. Light moves at a constant and known speed so the LiDAR instrument can calculate the distance between itself and the target with high accuracy. By repeating this in quick succession the instrument builds up a complex 'map' of the surface it is measuring (ibid). Using Professional drones, airborne LiDAR facilitates the collection of a multiplicity of data and tests them together to ensure accuracy. As the sensor is mobile and in constant movement, its height, location and orientation of the instrument must be always measured to determine the position of the laser pulse at the time of sending and the time of return. With tripod LiDAR a single GPS location and benchmark can be added for each location where the instrument is set up (CHIN ibid).

Photogrammetry, on the other hand, has emerged as the leading application for the creation of virtual archives of ancient artefacts and objectives in modern and national museums. It is the science of making measurements from photographs that translated images into $3 \mathrm{D}$ navigable objects. Its outputs are mostly 3D models, maps, drawings or measurements. To record archaeological sites or objects using photogrammetry, there is a need for both Aerial Photogrammetry and Close-Range Photogrammetry. In the former, the camera is mounted in an aircraft or on a drone. Multiple overlapping photos of the ground/building/ site are taken along a flight path and at specific but regular distances. These photos are processed in a stereo-plotter and then used in automated processing for Digital Elevation Model (DEM) creation. In Close-range Photogrammetry the camera is close to the subject and produces drawings, 3D models, measurements and point clouds. This type of photogrammetry (CRP for short) is also sometimes called Image-Based Modelling.

\section{NAVIGATING HISTORIC CITIES}

To practically investigate the application of virtual heritage, I would like to focus on recently developed British case studies. The first is designed by colleagues at the University of Edinburgh to develop a virtual time travel of Pre-Reformation Edinburgh. Completed in 2017 by Alan Miller \& Keith Millican of the School of Computer Science \& Smart History at the University of Edinburgh, The virtual reconstruction of pre-reformation Edinburgh has evolved out of collaboration between historians and computer scientists to investigate an important layer of the city's history. Visitors and residents of Edinburgh are offered the opportunity to see the city as it was just prior to the reformation. Miller and Millican used mobile phones and the Google Day dream platform to produce an onsite dual reality experience. As visitors explore the sites of Edinburgh, they can see its historic layers using their digital time travel binoculars. The app they developed is a comprehensive reconstruction of parts of the city and allows the visitors to move along a series of houses and streets. It is mobile and orientation aware, automatically delivering the correct view with a map interface that offers an equally engaging experience for remote virtual visitors.

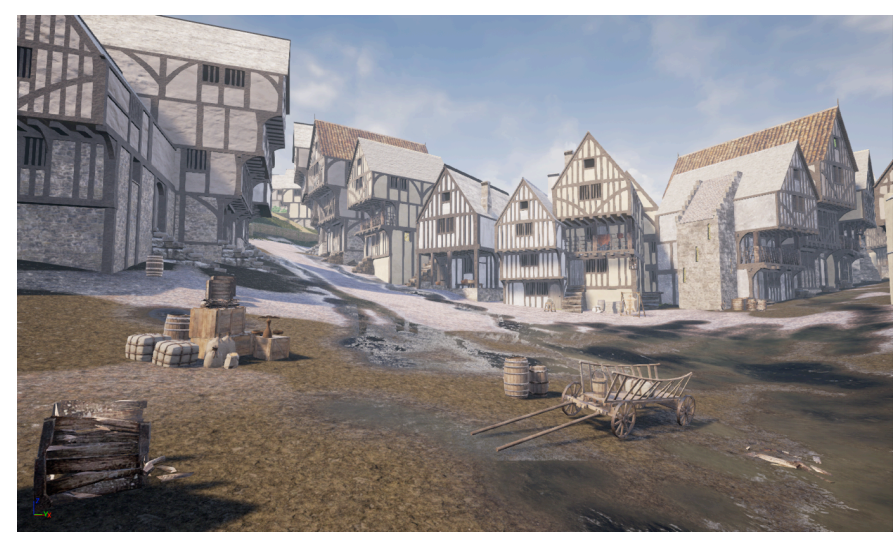

Figure 2. Pre-reformation Edinburgh Virtual Model. (Online source: Jordanstone College of Art and Design)

Similarly, Jarlshof in the Shetland Islands is a short computer-generated film by Kieran Baxter that offers research-led analytical narratives of the story of settlement at the Shetland Islands' archaeological site, using speculative scenarios and built structures from different historic eras (Baxter 2014.) The project was funded by Historic Scotland, as part of $\mathrm{PhD}$ research at Duncan of Jordanstone College of Art and Design, University of Dundee. It was completed in 2016 and has won the Arts and Humanities Research Council (AHRC) research awards for the same year. Baxter based his film on aerial photographs taken from a kite-suspended camera over the site, inserting and overlaying the speculative reconstructions of disappeared buildings mapped towards aerial photographs of other sites across Scotland. Using limited reconstructed elements and incorporating photographic and cinematic considerations, the interpretation of the archaeological narrative was conveyed into a visual toolkit for storytelling (ibid.)

In maximising the experiential value of visiting the site, lighting and weather conditions essentially play an active part in the narrative. The weather conditions were artificially and artistically reproduced in the animated outcome and derived from a combination of simulation and gathered imagery to reinforce the narrative by reflecting both the radical change in architectural style brought by the arrival of Norse culture, as well as the northern climate of the settler's origins. The virtual experience of the site required the use of a range of reconstructed elements to serve the aim of producing an aesthetic that would be both immersive and evocative in a speculative portrayal of lost structures. "The combination of aerial photography and computer-generated imagery used in 'Jarlshof' results in a highly technical image" (ibid.). It is important, hence, to suggest the speculative and artificial nature of the reconstructed elements while blending them into 
the surviving remains. Having the reconstructed structures slowly fade in and out of the scene was a helpful tool in offering layered spatial experiences of the site, while at the same time implying that the imagery had been technically manipulated.

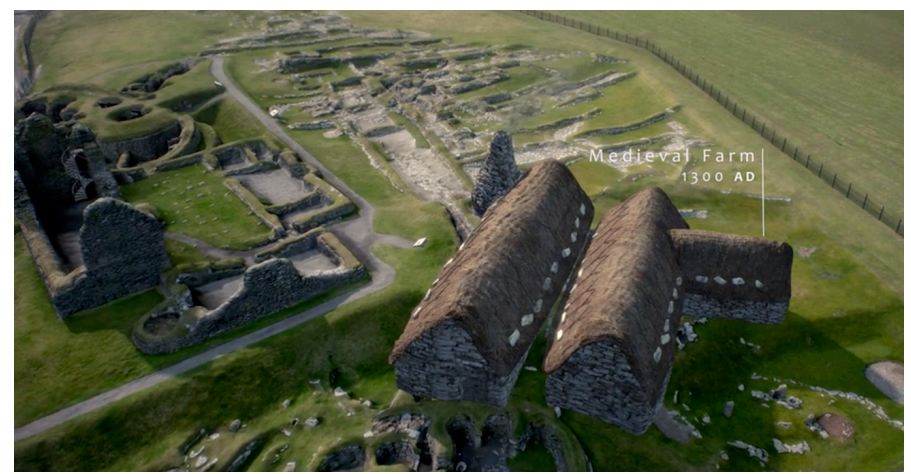

Fig 3. Kieran Baxter's Jarlshof, Shetland Islands computer-generated film (Source: http://www.topofly.com)

The aerial view reveals the structure and components of the site, parts of which are difficult to grasp from ground level. According to Baxter, the low altitude aerial perspective used in 'Jarlshof' "was intended as a compromise between the relatable ground-level view and the revealing yet distancing qualities available from high altitude" (Baxter 2014). Camera movement was used to enhance the viewer's perception of depth and the 3D depth and structure of the site. This format bears no resemblance to the normal experience of moving around Jarlshof on foot. Rather, the depth of the site's structure provided by the flying motion enhances the viewer's sense of the three-dimensional space. The camera was also used to create a sense of progression through the distinct chronological phases of the site through the interesting and annotated interplay of views, camera movement and chronological display.

The project has a very distinctive quality in the form of a simple and clear narrative of the site's chronology display what helps the ordinary and non-specialist audience, including children, to grasp the overall story of the site and its historic evolution including the phasing and changes in architecture. Moreover, the speculative nature of the reconstructed elements was reiterated in a text caption that details the other sites that were used to inform the reconstruction

\section{Navigating Historic Cities In The Middle East}

Two projects in particular provide evidence on the growing interest and expertise in the Virtual heritage in the Middle East Historic Cities. The first is the virtual modelling and Egyptian History interface developed by the Egyptian Centre for Documentation of Cultural and Natural Heritage, called Culturama. It is a display that allows the presentation of a wealth of data layers, where the presenter can click on an item and go to a new level of detail. The hardware part contains a huge 180 degrees panoramic interactive computer screen with a diameter of 10 meters that consists of nine separate flat screens arranged in a semi-circular shape and nine video projectors controlled by a single computer. Interactive multimedia software was especially developed to enable the display on the panoramic screen. This technology has proved to be an excellent tool for delivering information to children and adults. It has increased public awareness of Egypt's heritage using all available modern technology and helped to build capacities of professionals in the fields of conservation and documentation of cultural and natural heritage.

The Second project is HIP Pyramid Scan. In parallel to the exploration missions, the company Iconem realized a photogrammetry campaign using drones and laser scanners, to rebuild the Giza plateau and the site of Dahshur with all their monuments in $3 \mathrm{D}$, with a unique centimeter precision. This campaign is entirely dedicated to the advancement of knowledge either to restore or to discover pyramids. It is implemented by a team of international professional experts. The laboratory of the Japanese team, dedicated to the development and analysis of the images captured by muons radiography, has already been installed in Cairo. If these technologies are effective, they can even be implemented in other countries. Two-infrared thermography was used to establish a thermal map of the pyramids to reveal differences in density and to identify any voids behind the faces of the pyramids. Additionally, there are two missions using muons radiography that aim to verify and accurately visualize the presence of unknown structures within the monuments.

Virtual Heritage Cairo Project also develop a series of Four Virtual Heritage platforms for the use of virtual reality models of historic monuments in the medieval Islamic Cairo. Those included Sultan Hasan Mosque, Bayt Al-Suhaimy, Shar'i AL-Muizz and Souq Al-Khayamiyyah. Each building street has been used as a case studie for scanning and photogrammatery exercise to generate a virtual realty model of the historic environments. Al-Muizz virtual Tour, has been awarded best Mobile App for Virtual reality in Egypt by Samsung Egypt for 2017. Visitors used the virtual tour app to navigate through the historic monuments of the medieval city. Al-Khayammiay VR Model has provided an insight into the methods and ways through which rug trades could be reproduced virtually to generate income through virtual platforms.

The Digital record of Petra Historic Site in Jordan, as part of Zamani Project, proved very effective in its sustainable preservation. This project is part of the African Cultural Heritage Sites and Landscapes Database. It has been run by a research group at the University of Cape Town since 2005, and has been spatially documenting heritage sites in Africa and the Middle East. They acquire models, present and manage spatial and any other data. A large database of spatial material has been generated over this time. This data has been widely used by heritage and conservation experts to manage and conserve these sites. The virtual tour in this project is designed to allow interactive virtual walk-through sites using 
the spatial data. The project allows users to check virtually online: 3D model viewer and texturing, virtual tour, topography in the virtual tour (laser scan), panorama tours, GIS layouts, architectural drawings, and videos.

\section{CONCLUSION}

The London Charter for the Computer-based Visualisation of Cultural Heritage developed its first draft, in 2006, as "a means of ensuring the methodological rigour of computer-based visualization as a means of researching and communicating cultural heritage. Also sought was a means of achieving widespread recognition for this method". (London Charter.org, 2017). The Charter introduces a set of principles which, when adopted, would ensure that digital heritage visualisation is seen to be at least as intellectually and technically rigorous as longer established cultural heritage research and communication methods (ibid). The challenge of scholarly validation of heritage visualization is similar to those facing media and art productions in that some subjects, and arguments, do not so readily lend themselves to textual description and author's work and product are inherently nonlinear or synthetic. The production, be it a visualization, expressive medium of choice, reflects the author's perception as integrated in the selective production process itself, be it a static image, real-time model or printed object (Denard 2012).

The effort to address and organise the industry and practice of virtual heritage needs to address the use of visualizations through influencing not only research, academic and curatorial contexts, but also those aspects of the media and entertainment industry involving the reconstruction of architectural and cultural heritage. Computer-generated visual interpretation of history and culture plays an increasingly influential role in shaping public perceptions of the past, despite being highly selective, subjective and in many instances inaccurate. It is of considerable importance that a generation's impressions of the past should integrate the contours of historical understanding. The commercial and industrial sectors, hence, need to work on documentaries and other media productions to enable users and audience to distinguish between fact and fiction (ibid).

The past did not happen in 2D and it, therefore, cannot be effectively studied or taught as a series of disconnected and selective still images that display incomplete aspects of one coherent and missing story. The development of an interactive, 3D platform that will enable people to re-live history in a reconstructed environment is the best way for them to engage and understand how medieval cultures existed, lived or to grasp the implications of the evidence that we have (Sanders 2008). It is also true that this reconstructed world would be contested as based on different and at times disputed accounts and evidences. History after all is a subjective matter. Nevertheless, the argument-driven nature of historical evidence would be better scrutinised through examining events within 3-dimentional environments.
But the main argument to be developed is to engage with archaeologists, who are conventionally wary of technologies, to embrace it to their advantage as assistive tools to see the ancient world in realistic settings and environments. This would not only support the documentation of specific physical aspects of history, it would offer unprecedented opportunity to test theories, findings and narratives in virtual environments. It would also engage a much broader range of audience, like children, school pupils, old people and nonspecialist ordinary people. The power of the moving image, animation and virtual environment has attracted wide interest in understanding the past that was otherwise very limited.

This research report aimed at offering a comprehensive overview on global practices, theories and technologies used for the digital documentation and interpretation of architectural and cultural heritage through virtual environments. It has provided a brief history of the emergence and evolution of virtual heritage while giving an account of 12 selective and best practice case studies in the field. This report has shed light on the importance, if not dominance, of virtual documentation of endangered heritage sites over the past decade.

\section{ACKNOWLEDGMENT}

The author would like to acknowledge the generous support of the Arts and Humanities Research Council (AHRC), who funded the research reported in this paper under Grant Ref: AH/N009347/1. We also acknowledge the generous support and help of the Ministry of Antiquities in Egypt and the National Research Institute of Astronomy and Geophysics. This paper includes exerts of research from the funded project, "Virtual Heritage of Medieval Culture", which have previously appeared in the project publications and reports.

\section{REFERENCES}

[1] Abdelmonem, M.G., 2016a, "The Architecture of Home in Cairo: Sociospatial practice of the Hawari's Everyday Life", London: Routledge

[2] Abdelmonem, M.G., 2016b, "The Modern Ordinary: Changing culture of living in Egypt's traditional quarters at the turn of the twentieth Century". Middle Eastern Studies, Vol. 51, No. 6

[3] Abdelmonem, M.G., Selim, G., 2012, Architecture, Memory and Historical Continuity in Old Cairo, The Journal of Architecture, Vol.17, issue 2, pp163-189.

[4] Abdelmonem, M.G., 2012, "Responsive homes of old Cairo: Learning from the past, feeding in the future". The Journal of Hospitality and Society Vol. 2, No. 3; pp251-271

[5] Addison, A.C., 2000, "Emerging trends in virtual heritage", IEEE multimedia 7 (2), pp.22-25

[6] Baxter, K, 2014, "Jarlshof Lost and Found: Low altitude aerial photography and computer-generated visualisation for the interpretation of the complex settlement remains found at Jarlshof, Shetland". Internet Archaeology, (36). http://dx.doi.org/10.11141/ia.36.1

[7] Barack, L., 2009, "Rome Reborn". School Library Journal [online], 55(3), pp. 15-n/a Available at: $<$ http://wk6kg9sd8m.search.serialssolutions.com/?ctx_ver=Z39. 
[8] Bentkowska-Kafel, A., Denard, H., \& Baker, D. (2012). Paradata and transparency in virtual heritage. Farnham, Surrey, England: Ashgate.

[9] Ch'ng, E., Gaffney, V., Chapman, H. (eds.), 2013, "Visual Heritage in the Digital Age", Springer Series on Cultural ComputingLondon: Springer-Verlag London

[10] Champion, E., 2016,"Critical Gaming: Interactive History and Virtual Heritage", London: Routledge.

[11] Charara, S., 2017, "How Does VR really work?", Wareable, online article, 23 Feb 2017.

[12] Canadian Heritage Information Network (CHIN), 2008, “3D Pilot Project - Complementary Physical and Virtual Experiences with 3D Objects”. $\quad$ Accessed $10 \quad$ March 2017. http://canada.pch.gc.ca/eng/1443455392917

[13] Denard, H., 2012, "A New Introduction to the London Charter" in A. Bentkowska-Kafel, D. Baker \& H. Denard (eds.) Paradata and Transparency in Virtual Heritage Digital Research in the Arts and Humanities Series (Ashgate, 2012) 57-71. (C) Ashgate 2012. Reproduced by permission

[14] Dhillon, S., 2016, "What a venture capitalist sees in the virtual and augmented reality market", online article, 5th October 2016. (www.recode.net)

[15] DigiArt, 2017, EU- Horizon 2020 Project, DigiArt website: http://digiart-project.eu/consortium/certh/, accessed on 30th March 2017

[16] Enrico, D and Matteo, M., 2013, "Virtual Aquileia France: IGITAL Heritage". Available at: <http://www.digitalheritage2013.org/virtualaquileia/>.

[17] eNumerate, 2015, EU Annual report on the Digitisation in Cultural Heritage, Online Document accessed via : https://www.townswebarchiving.com/2015/

[18] Frischer, B., 2013, "Rome RebornRome": Available at: $<$ http://romereborn.frischerconsulting.com/about.php>.

[19] Gabbellone, F., Tanasi, D., Ferrar, I., 2013, "Virtual Archaeology and Historical Revisionism; The Neglected Heritage of Greek Siracusa". International Conference on Cultural Heritage and New Technologies pp. 1-16.

[20] Goodrick, G., Gillings,M., 2000, 'Constructs, Simulations and Hyperreal Worlds: The Role of Virtual Reality (VR) in Archaeological Research', in Gary Lock and Kayt Brown (eds), On the Theory and Practice of Archaeological Computing (Oxford, 2000), pp. 41-58;

[21] Guttentag, D.A. (2010) Virtual reality: Applications and implications for tourism. Tourism Management [online], 31(5), pp. 637-651 Available at: $<$ http://www.sciencedirect.com/science/article/pii/S0261517709001332 $>$.

[22] Henriot, C. (2016) Virtual ShanghaiChania: Institut de Recherches Asiatiques, Aix-Marseille University; Institut Universitaire de France. Available at: $<$ http://www.virtualshanghai.net/>.

[23] Ioannides, M., et. Al, 2016, "Digital Heritage: Progress in Cultural Heritage. Documentation, Preservation and Protection", 6th International Conference, EuroMed 2016, Nicosia, Cyprus, October 31 - November 5, 2016, Proceedings, Part II

[24] Kidd, J., 2015, "Museums are using virtual reality to preserve the past before it's too late", The Conversation, July 14, 2015

[25] Louis S. Gerteis, Andrew Hurley, Laura Westhoff and W. Davis Van Bakergem (2014) The St. Louis Regional History ProjectUnited States:
University of Missouri-St. Louis, Institute for Museum and Library Services, National Endowment for the Humanities, and Missouri State Library. Available

$<$ http://www.umsl.edu/virtualstl/phase2/indexBAK.html $>$.

[26] Madary M., Metzinger, T.K., 2016, "Real Virtuality: A Code of Ethical Conduct". Recommendations for Good Scientific Practice and the Consumers of VR-Technology. Front. Robot. AI 3:3. doi 10.3389/frobt.2016.00003

[27] Mosaker, L., 2001, Visualising Historical Knowledge Using Virtual Reality Technology, Digital Creativity, 12: 15-25.

[28] Millier, A. Millican, K, 2016, "Virtual time travel in pre-reformation Edinburgh", University of St. Andrews: http://epsrc-showcase.wp.standrews.ac.uk/2016/12/01/virtual-time-travel-in-pre-reformationedinburgh-premiere/ (accessed on 15th March 2017)

[29] Pujol, L., Champion, E., 2013, "Evaluating presence in cultural heritage project", International Journal of Heritage Studies, Vol 18, Issue 1, pp.83-102

[30] Ridge, M., Birchall,D., 2015, "How digital tech can bridge gaps between museums and audiences", Cultural Professional Network Article, the Guardian Online, Published on 23 October 2015, (accessed on 13 March 2017: < https://www.theguardian.com/culture-professionalsnetwork/2015/oct/23/digital-technology-museums-audiencescollaboration>

[31] Roberts, J. C, Ryan, N.S., 1997, 'Alternative Archaeological Representations within Virtual Worlds', in Richard Bowden (ed.), Proceedings of the 4th UK Virtual Reality Specialist Interest Group Conference, Brunel University, Uxbridge, Middlesex, November (1997), pp. $179-88, \quad$ available at www.cs.kent.ac.uk/people/staff/nsr/arch/vrsig97/vrsig.html;

[32] Robin B. Williams, Greg Johnson, Léon Robichaud and Christopher Hendricks (2016) Virtual Historic Savannah ProjectUnited States: Savannah College of Arts and design, National Endowment for the Humanities. Available at: <http://vsav.scad.edu/>.

[33] Roger L. Michel Jr (2016) Institute for Digital Archaeology Museum of the Future Dubai, University of Oxford, UNESCO World Heritage, Harvard University,UMASS BOSTON, Classics for All, Abraham Path and other organisations. Available at $<\mathrm{http}$ //digitalarchaeology.org.uk/our-purpose>.

[34] Sanders, D. 2008, "Why do virtual heritage?", Online Features Article, Archaeology Archive. Published on 13 March 2008. Accessed online via: http://archive.archaeology.org (10 March 2017)

[35] Stone, R., and Ojika, T., 2000, "Virtual Heritage: What Next?", IEEE multimedia 7 (2), pp.73-74

[36] Takase,Y. Yano, K., Nakaya, T. Isoda, Y. Kawasumi, T. Matsuoka, K. Seto , T. Kawahara , D. Tsukamoto , A. Inoue M. and Kirimura T., 2012, "Virtual Kyoto: Visualization of Historical City with 4dgis, Virtual Reality and Web Technologies". The International Society for Photogrammetry and Remote Sensing .

[37] Virtual Museums Canada (VMC) 2017, "Supporting the Developmen and Presentation of Digital Heritage Content", VMC Website \& Online Reports: http://www.rcip-chin.gc.ca/apropos-about/rapports-reports/

[38] Yang, C., Peng, D. and Sun, S., 2006, Creating a Virtual Activity for the Intangible Culture Heritage, in 16th International Conference on Artificial Reality and Telexistence-Workshops, ICAT'06, pp. 636- 